\title{
COMPORTAMENTO DE DIOPSIDITO SOB ATAQUE MICROBIANO
}

\author{
REGINA MARIA RIBEIRO* e MARIA ALBA FARIAS TANNER DE OLIVEIRA*
}

\begin{abstract}
Cultures of Aspergillus fumaricus and Penicillium rotundum isolated from soils, grown in Czapeck-Dox liquid, have shown the capacity to attack both diopside and hornblende, the principal components of diopsidite, colletect between Amaralina and Rio Vermelho beaches close to the Méridien Hotel (Salvador, BA). These rocks occur as enclaves in high grade metamorphic rocks, metamorphosed in granulite facies. The diopsidite is holomelanocratic, has a black color, is medium grained with a massive structure and has a granoblastic texture. The microorganisms cause ferric-iron, calcium and magnesium solubilization after three successive incubations, each of 90 days. Microscopically, it has been observed that Aspergillus fumaricus atacks more strongly than Penicillium rotundum, which, in turn, attacks more strongly than water, which, in turn, attacks more strongly than the culture medium. The minerals altered to amorphous materials not identified by a "standard" microscope. These products are light to dark grey or black in colour, isotropic. Is was observed that diopside alters more than horndlende and the last, more than plagioclase.
\end{abstract}

INTRODUÇÃo A flora microbiana presente nos solos e nas águas, devido a sua possibilidade de romper equilíbrios químicos e efetuar transformações de matéria à temperatura ambiente, contribui para alterações superficiais em minerais e rochas, e aumentar o intemperismo destes em relação às ações não-biológicas. A ação é indireta, que decorre de modificações introduzidas nos ecossistemas por produtos metabólicos, sobretudo produtos ácidos. É este o mecanismo de ação dos fungos, sempre presentes na flora normal de solos tropicais ácidos. Boyle \& Voigt (1967) verificaram que os ácidos cítricos e oxálicos produzidos por uma cepa de fungo Aspergillus niger provocava alteraçōes em cristais de biotita, com solução parcial do ferro e destruição da estrutura interna dos cristais. Estes mesmos autores, em 1973, investigaram os mecanismos de mobilização dos íons nas redes cristalinas de biotita, moscovita e microclina. Posteriormente, Ribeiro et al. (1976) estudaram a alteração de diabásio em culturas de cepa de Aspergillus niger isolada de um solo mineralizado a cobre do Estado da Bahia.

Amostras de horblenda diopsidito foram estudadas após as alterações causadas pelo crescimento dos fungos Aspergillus fumaricus e Penicillium rotundum - realizaram-se análises petrográficas e químicas do produto solubilizado durante três, seis e nove meses de incubação, antes e após o ataque microbiano.

ASSENTAMENTO GEOLógıco Os diopsiditos de Salvador (BA) ocorrem como enclaves elípticos em rochas metamórficas de. alto grau, metamorfizadas à altura da fácies granulítica (Tanner de Oliveira \& Conceição 1982). Regionalmente, fazem parte do Cinturão Granulítico Atlântico (Guimarães 1959, Loczy \& Ladeira 1976; Mascarenhas 1979), constituído essencialmente de rochas arqueadas, retrabalhadas pelo Ciclo Orogenético Transamazônico. Amostrou-se o hornblenda diopsidito que ocorre entre as praias de Amaralina e Rio Vermelho próximo ao Hotel Méridien, em Salvador (BA).

A rocha tem cor preta, é holomelanocrática, de granulação fanerítica média, com os grãos variando de 0,25 a 2,4 $\mathrm{mm}$, predominando $1,70 \mathrm{~mm}$; apresenta estrutura maciça e textura granoblástica a hipidioblástica; e o diopsídio é o constituinte maior $(62,4 \%)$, seguido da hornblenda
(28,77\%), hiperstênio $(5,2 \%)$, plagioclásio intermediário $(2,2 \%)$ e opaco $(1,5 \%)$ (Fotomicrografia 1a).

$\mathrm{O}$ diopsídio ocorre granoblástico a subidioblástico, verde-pálido, por vezes com textura poiquiloblástica, com contatos retos a curvos, extinção $\mathrm{Z} \Lambda \mathrm{c}=410$; passa retrometamorficamente para hornblenda com pleocroísmo $\mathrm{X}=$ verde-oliva, $Y=$ verde-amarelado e $Z$ = verde-acastanhado, onde $Z>Y>X$; o diopsídio inclui e associa-se a hiperstênio com pleocroísmo distinto, verde-pálido a rosa; e tanto este como aquele alteram-se em clorita fibrosa mais opaco.

O plagioclásio é andesina, ocorre intergranular, zonado inversamente, tendo no núcleo teor de $\mathrm{An}=39 \%$ e na periferia $\mathrm{An}=52 \%$; e o opaco ocorre xeno a subidioblástico, intergranular ou incluso, e é provavelmente magnetita.

MÉTODOS MICROBIOLÓgICOS Os microorganismos utilizados foram escolhidos entre 50 fungos isolados do solo de Morro do Chapéu (BA).

Os gêneros Aspergillus e Penicillium foram especialmente selecionados devido não só à sua grande abundância no referido solo como também a sua grande repartição em outras regiōes, como foi mostrado em trabalhos já citados. Foram cultivados no meio orgânico de Sabourad (Glucose 2\% e peptona $1 \%$, com $\mathrm{pH}=5,6$.

As experiências foram feitas em frascos erlenmeyers de $300 \mathrm{ml}$, contendo $100 \mathrm{ml}$ do meio de cultura (meio mineral + sacarose (3\%), segundo Czapeck-DOX), com pH 7,2 a 7,4 mais $5,0 \mathrm{~g}$ da rocha triturada em frações $>0,50<1,00 \mathrm{~mm}$, além da lâmina delgada. Foi usado como inóculo $(0,5 \mathrm{ml})$ uma suspensão de esporos obtidos por cultivo em tubo de gelose Sabourad, a $30^{\circ} \mathrm{C}$ por sete dias, calibrada para absorbância de 0,8 em $570 \mathrm{~mm}$, em fotocolorímetro Linson 3. Os frascos foram incubados em estufa bacteriológica, em repouso a $30^{\circ} \mathrm{C}$, durante 90,180 e 270 dias, com ou sem ataque microbiano. Em trabalhos anteriores Ribeiro et al. (1976) verificaram que a fonte energética (sacarose) esgotava-se de 25 a 30 dias; por esta razão adicionaram-se mensalmente, em cada erlenmeyer, $10 \mathrm{ml}$ da solução de sacarose a $30 \%$. Investigou-se também a ação da água sobre amostras e lâmina delgada de rocha, para avaliar a atuação da mesma no processo de alteração.

* Departamento de Geoquímica do Instituto de Geociências da Universidade Federal da Bahia, Rua Caetano Moura, 123, CEP 40000, Salvador, BA, Brasil. 
No fim de cada tempo de incubação, o conteúdo dos fracos era filtrado através de papel Whatman n.o 41 e lavado numerosas vezes com água deionizada. $\mathrm{O}$ volume do filtrado, ajustado ao valor inicial por evaporação a $100^{\circ} \mathrm{C}$, foi usado para as dosagens químicas de ferro, cálcio e magnésio. O mesmo procedimento foi realizado com os controles estéreis (testemunho) constituídos de amostra de rocha, lâmina delgada e o meio de cultura. Os fragmentos frescos e alterados da rocha foram lavados exaustivamente e submetido à análise química por espectrofotometria de absorção atômica. As lâminas delgadas da rocha também foram cuidadosamente lavadas com água deionizada e estudadas microscopicamente.

\section{MICROSCOPIA DA ROCHA ALTERADA Aspergillus} fumaricus

- Com 90 dias de incubação, a rocha mostrou-se parcialmente alterada, de forma irregular, com concentrações de ferro (opaco), por vezes interligando-se. O diopsídio foi o mineral mais sensível ao ataque, alterado em material isotrópico de cor branca. As alterações processaram-se na seguinte ordem: diopsídio $>$ hornblenda $>$ plagioclásio > opaco; esta observação é uma constante
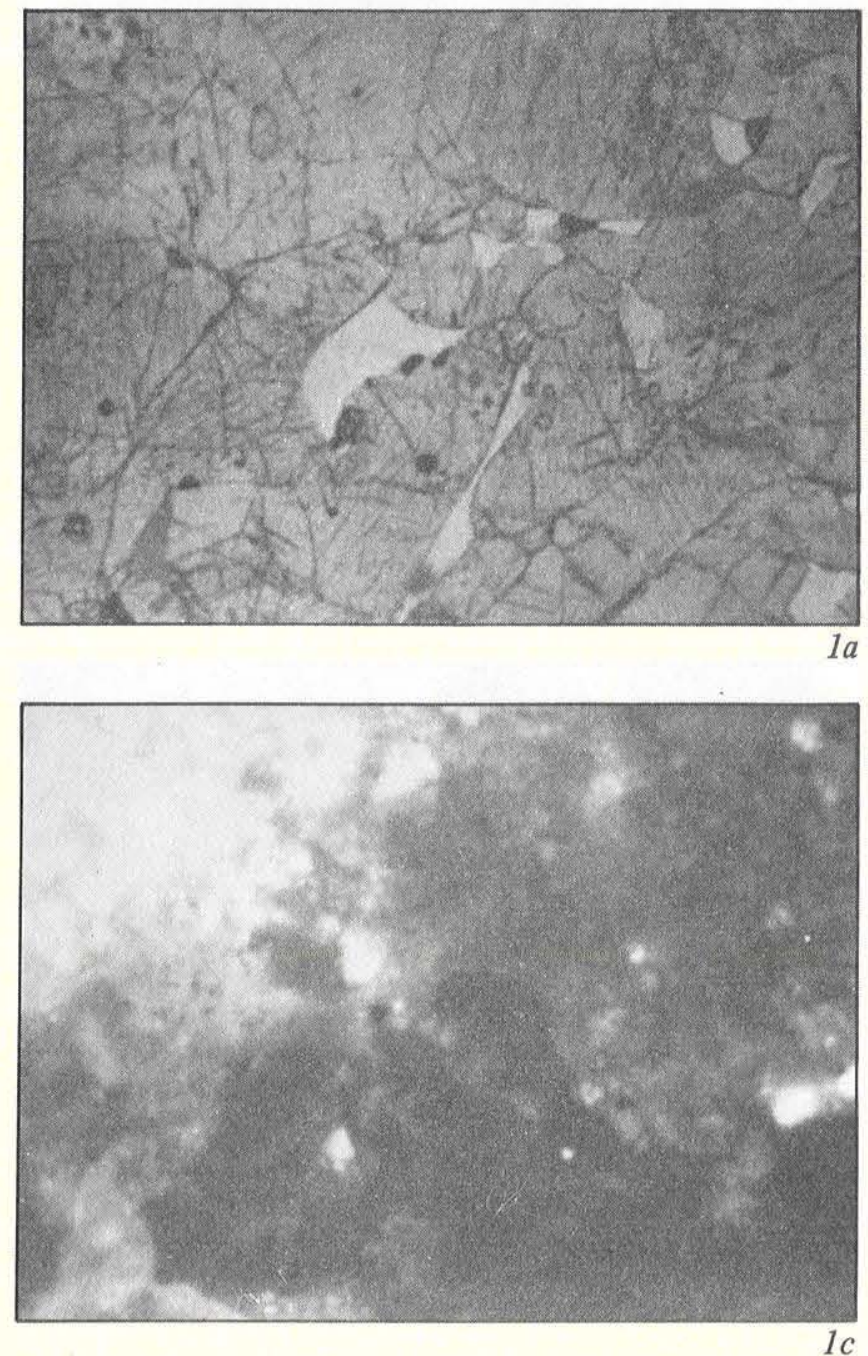

em todas as fases de pesquisa (Fotomicrografia 1b).

- Com 180 dias de incubação, a rocha encontra-se totalmente alterada, exceto nos bordos dos grãos que se encontram nas bordas da lâmina. Em luz plana, o diopsídio mostra cor cinza mais clara que a hornblenda. Os contatos são parcial ou totalmente destruídos, aparecendo no local um material de cor mais clara (Fotomicrografia 1c).

- Com 270 dias de incubação, a rocha apresenta-se menos alterada que a fase anterior (Fotomicrografia ld).

\section{Penicillium rotundum}

- Com 90 dias de incubação, observou-se uma atuação maior que a causada pelo fungo anterior, uma vez que cerca de $45 \%$ da rocha encontrava-se totalmente alterada em material de cor cinza-escuro, isotrópico; e os $55 \%$ restantes acharam-se parcialmente alterados sob a forma de concentrações de opaco, irregularmente interligados (Fotomicrografia 2a).

- Com 180 dias de incubação, muito pouco restou da lâminá delgada da rocha, que se alterou totalmente em material de cor cinza-claro e cinza-escuro, isotrópico.

- Com 270 dias de incubação, o ataque microbiano foi tão intenso que destruiu a lâmina delgada da rocha.
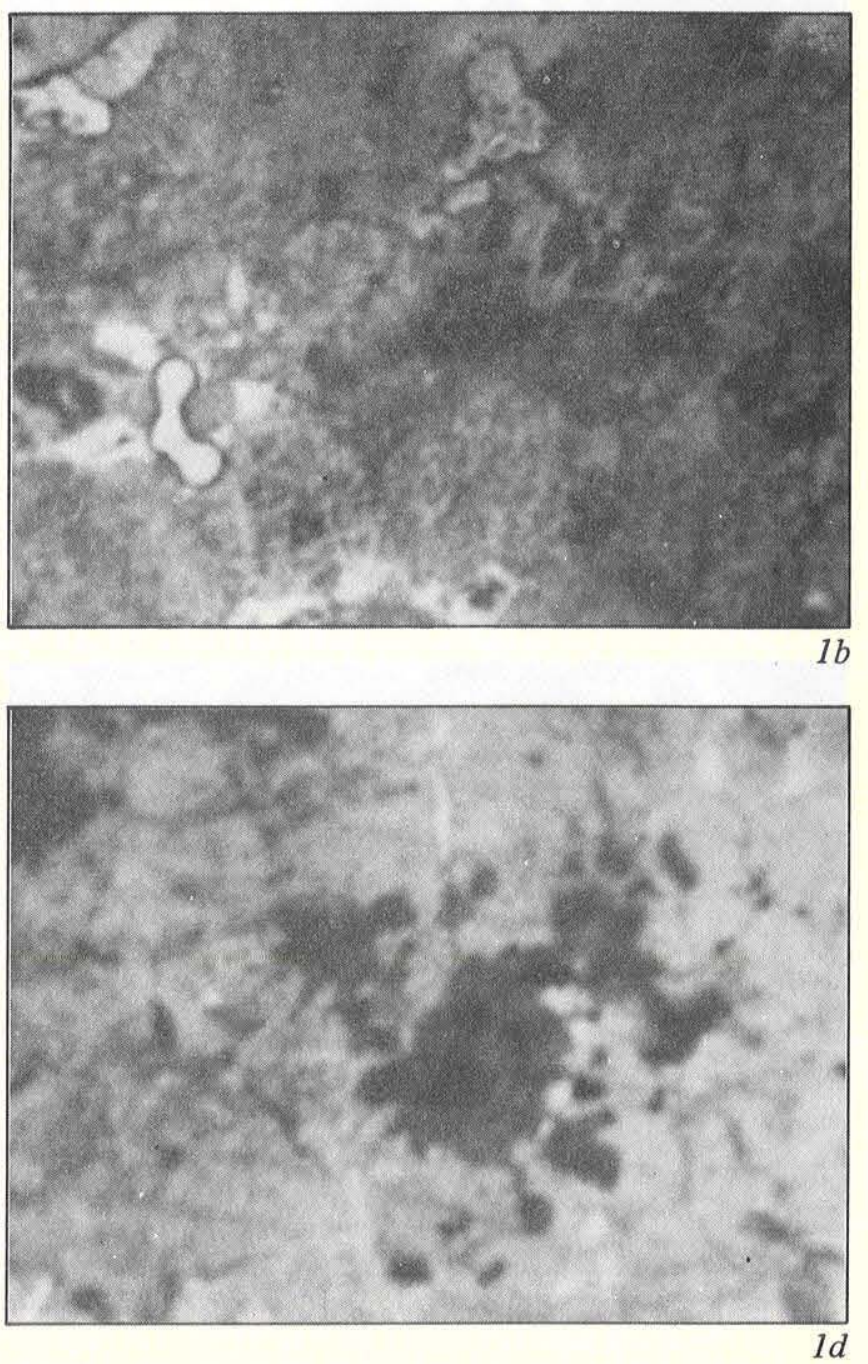

Prancha 1 - Fotomicrografias - Aumento 20X e nicóis paralelos: 1a. Aspecto geral do diopsidito; 1 b. Ação do Aspergillus Fumaricus, num periodo de 90 dias: o diopsidito encontra-se bastante alterado; 1 c. Idem num periodo de 180 dias; a rocha alterada; 1 d. Idem num periodo de 270 dias: a rocha apresenta-se menos alterada. 


\section{Testemunho}

- Com 90 dias de incubação, a rocha encontrou-se alterada superficialmente nas fraturas e planos de clivagens, em material translúcido de cor cinza-escuro, por vezes quase opaco (Fotomicrografia 2b).

- Com 180 dias de incubação, a rocha guardava as mesmas características observadas com 90 dias, só um pouco mais alterada em material de cor cinza-escuro, translúcido, principalmente no interior dos grãos (Fotomicrografia 2c).

- Com 270 dias de incubação, a rocha encontrava-se mais alterada, observando-se apenas as propriedades em ortoscópio nos bordos dos grãos (Fotomicrografia 2d).

\section{Água}

- Com 90 dias de incubação, a rocha exibia alteração parcial; aqui, a hornblenda alterada é bem observada em luz plana, uma vez que mantém forma e cor, a despeito de mostrar-se isotrópica em ortoscópio (Fotomicrografia 3a).

- Com 180 dias de incubação, a rocha apresentava-se bastante alterada; só nas bordas os grãos mostram algu-
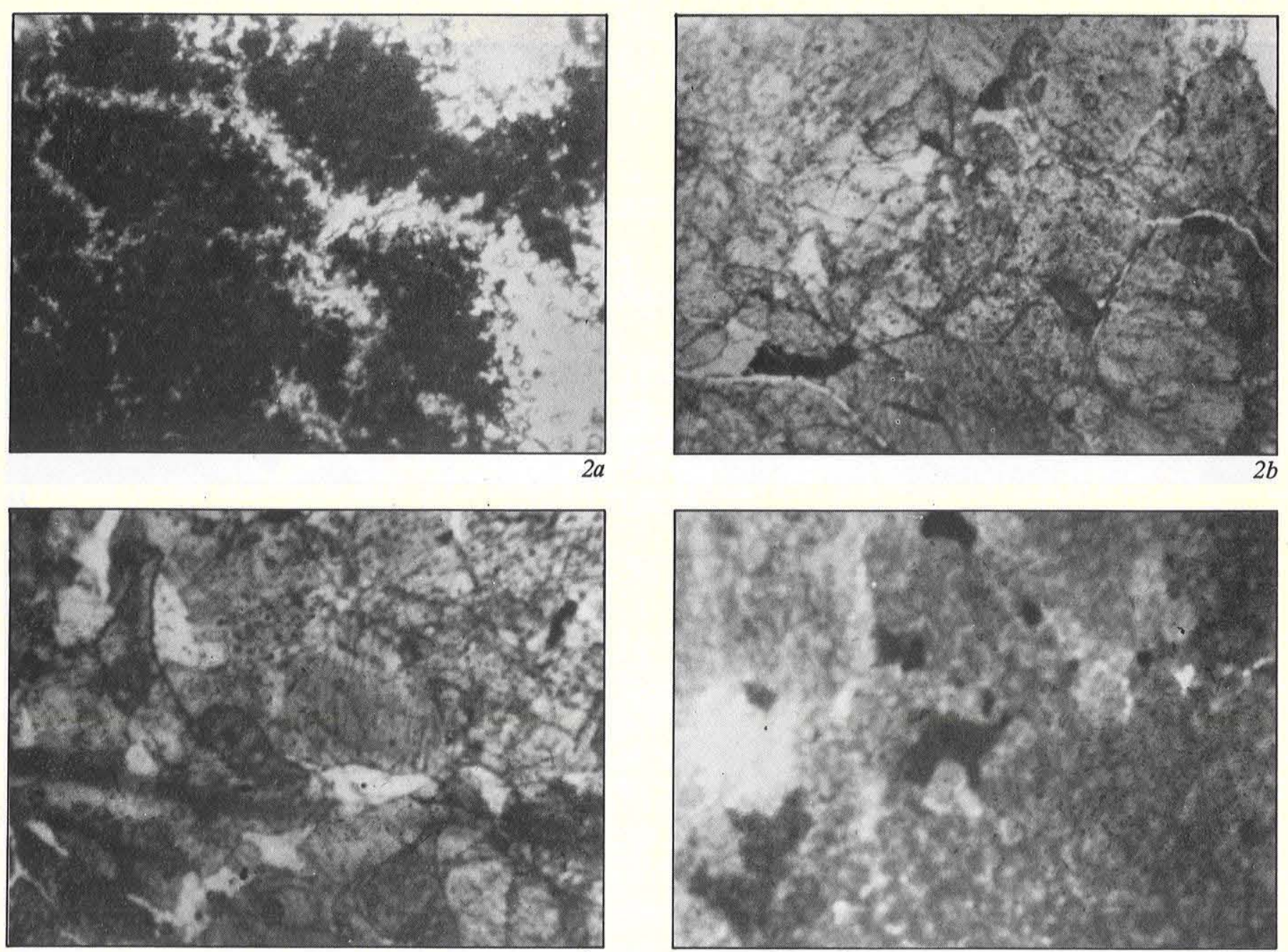

$2 c$ mas de suas propriedades. Em luz plana exibe cor cinzaescuro translúcida e em ortoscópio é isotrópico (Fotomicrografia $3 b$ ).

- Com 270 dias de incubação, a rocha mostrou-se mais alterada que nas fases anteriores, observando-se exclusivamente os contatos entre os grãos, seja em luz plana ou com os nicóis cruzados (Fotomicrografia 3c).

RESULTADOS ANALI'TICOS Fez-se a dosagem de $\mathrm{Ca}^{++}, \mathrm{Mg}^{++}$e Fe $\mathrm{Fe}^{+++}$na rocha sã e alterada, nas várias etapas das experiências realizadas. O hornblenda diopsidito fresco apresentou os seguintes resultados: $\mathrm{CaO}=11,42 \%$, $\mathrm{MgO}=12,95 \%$ e $\mathrm{Fe}_{2} \mathrm{O}_{3}=18,02 \%$.

$\mathrm{Na}$ tabela 1 são mostrados os teores de $\mathrm{Ca}^{++}, \mathrm{Mg}^{++} \mathrm{e}$ $\mathrm{Fe}^{+++}$solubilizados em cada período de incubação, seja em meio estéril, seja em presença de Aspergillus fumaricus ou do Penicillium rotundum; também está indicado o $\mathrm{pH}$ do líquido dos solubilizados e da extração pela água (independente da ação dos microorganismos e do meio de cultura). A ação microbiana se exprime pela diferença entre o tratamento microbiano e o testemunho estéril.

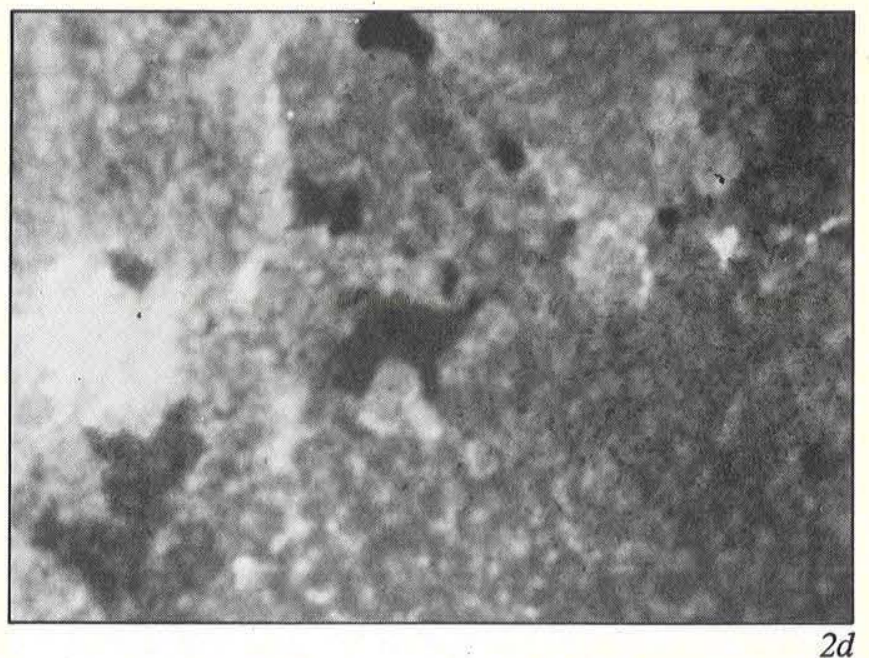

Prancha 2 - Fotomicrografias - 2a. Ação do Penicillium rotundum, num periodo de 90 dias: a rocha bastante alterada, com os contatos dos grãos destrutdos; 2b. Testemunho com 90 dias: observa-se alteração superficial nas fraturas e planos de clivagens; 2c. Idem com 180 dias: alteração pouco mais intensa que aos 90 dias; $2 d$. Idem com 270 dias: a alteração é quase total. 

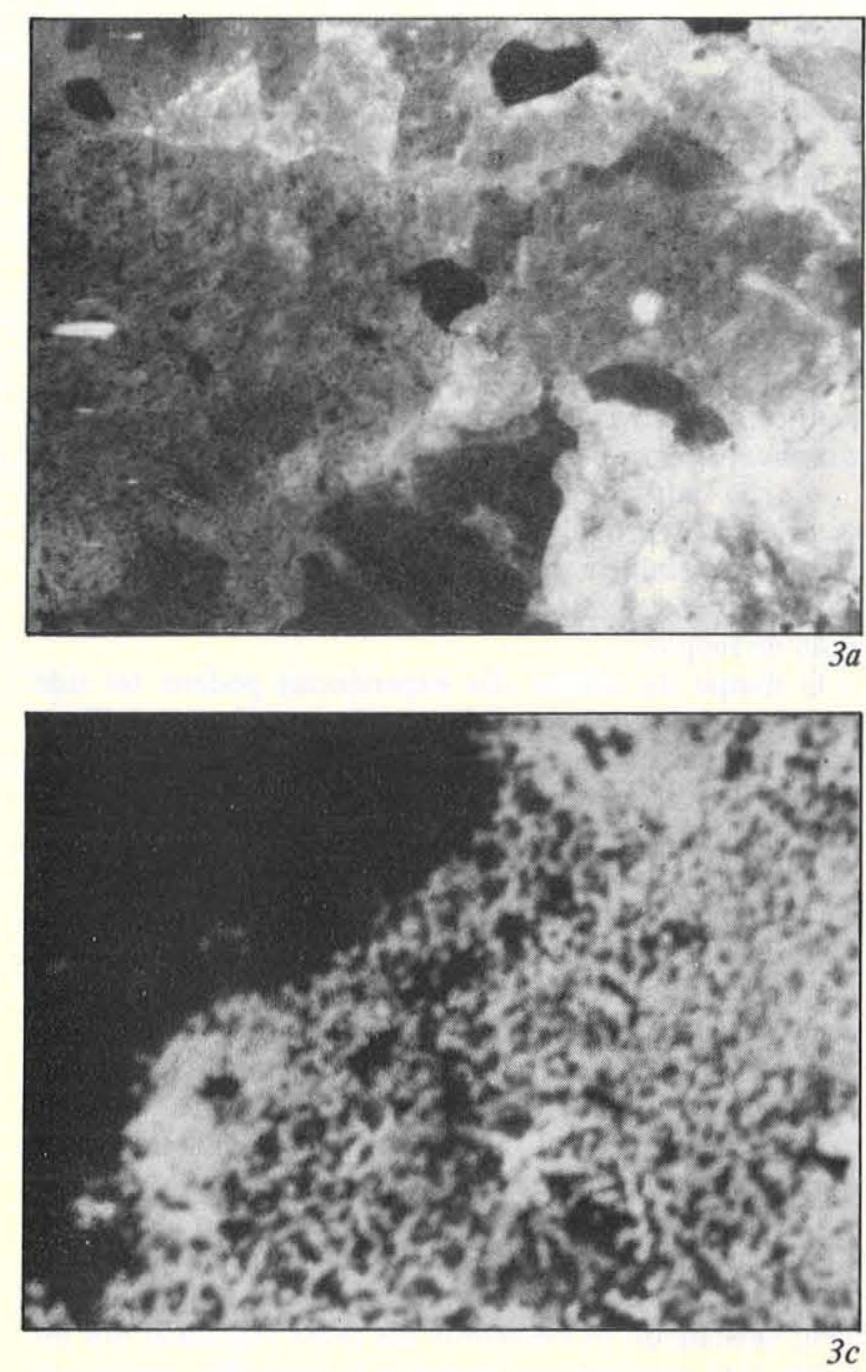

Tabela 1 - Solubilização do cálcio, magnésio e ferro. Extração pela água e variação do $\mathrm{pH}$ do liquido da alteração da rocha.

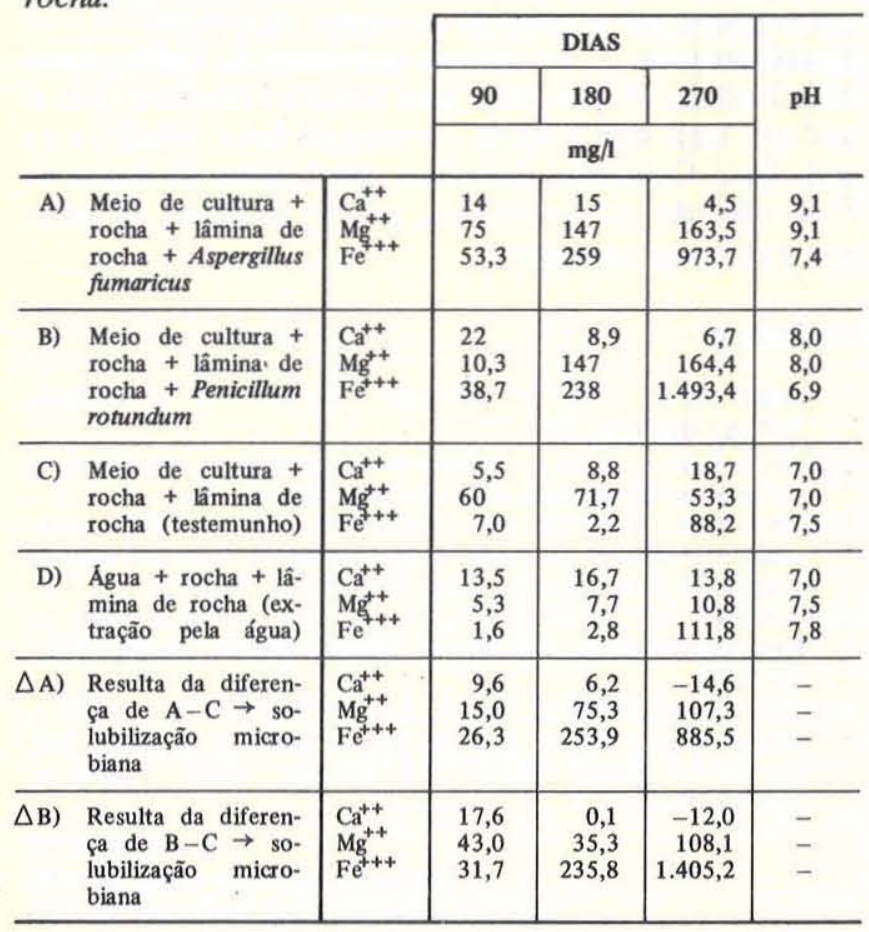

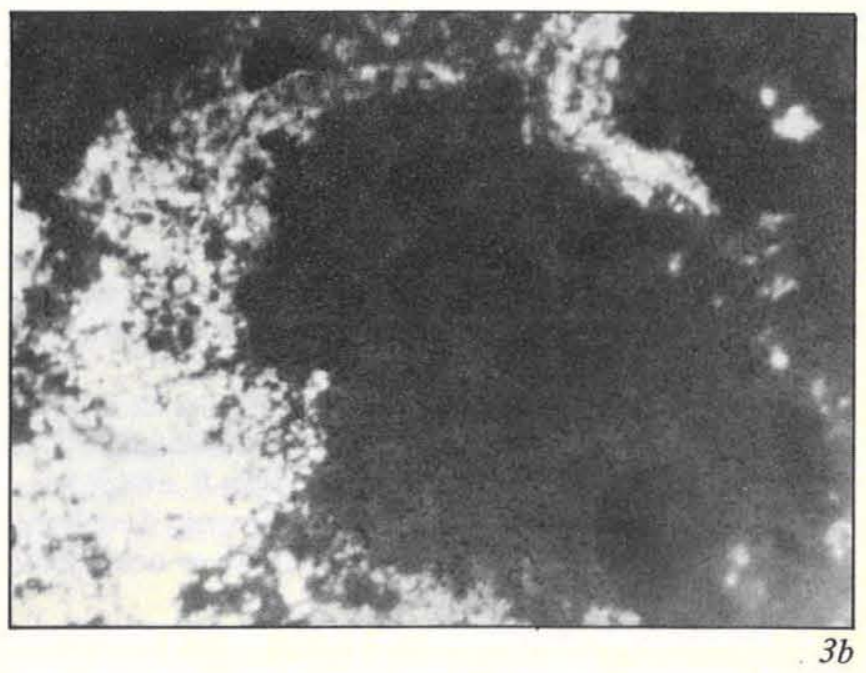

Prancha 3 - Fotomicrografias - 3a. Ação da àua num periodo de 90 dias: a rocha exibe alteração parcial; $3 b$. Idem num periodo de 180 dias: a rocha mostra-se bastante alterada, excetuando as bordas dos grãos; 3c. Idem aos 270 dias: a rocha apresenta-se mais alterada que nas fases anteriores.

DIScussÃo Aos 90 dias da experiência, quando se atingiu o máximo de extração nos ensaios A e B, a quantidade de $\mathrm{Ca}^{++}$extraída da rocha é 9,6 e $17,6 \mathrm{mg} / \ell$ maior que a extraída em ausência dos microorganismos no ensaio C.

Com 180 dias de incubação, a solubilização diminui no ensaio B, duplicando no ensaio C (Tab. 1).

Com 270 dias de incubação, notamos uma insolubilização microbiana. $\mathrm{O}$ teor de cálcio é decrescente, resultado que pode ser interpretado como decorrente da ação complexante exercida por produtos do metabolismo dos fungos.

A queda do cálcio com 180 dias (ensaio B) e 270 dias de incubação (ensaio A e B) pode ser interpretada da seguinte maneira: o meio de cultura usado é deficiente do íon $\mathrm{Ca}^{++}$e, como se sabe, a multiplicação do micélio de Aspergillus e Penicillium é proporcional, dentro de certos limites, ao teor de $\mathrm{Ca}^{++}$do meio, podendo ser usado até como método de dosagens (Ottow \& Klopotek 1969). O íon cálcio solubilizado da rocha supre a deficiência do cálcio do meio.

Outra hipótese é que, junto com o cálcio, foram extraídos outros elementos ativantes do crescimento dos microorganismos, pois estes são também influenciados pelos teores de cobre, manganês e zinco do meio (Ottow \& Klopotek op. cit.). Microscopicamente, a rocha mostrou-se menos alterada que na fase anterior (180 dias), o que implica o cálcio não ter sido solubilizado.

A extração do $\mathrm{Mg}^{++}$e do $\mathrm{Fe}^{+++}$aumentou com o tempo 
de incubação (Tab. 1). Aos 270 dias da experiência, foram solubilizados $107,3 \mathrm{mg} / \ell$ de $\mathrm{Mg}^{++}$da rocha. Quanto ao íon $\mathrm{Fe}^{+++}$, nota-se que a solubilização é cada vez mais concentrada, chegando a atingir $1.405,2 \mathrm{mg} / \ell$ no ensaio B, aos 270 dias de incubação. No ensaio A, a liberação é menos inten$\mathrm{sa}, 885,5 \mathrm{mg} / \ell$ (Tab. 1).

A ação da água é significativa, pois ela liberou mais de $13,8 \mathrm{mg} / \ell$ de $\mathrm{Ca}^{++}$, nas três fases de incubação; também liberou $10,8 \mathrm{mg} / \ell$ de $\mathrm{Mg}^{++}$e $111,8 \mathrm{de} \mathrm{Fe}^{+++}$aos 270 dias da experiência.

$\mathrm{O}$ pH se mantém alcalino com 90 e 180 dias de incubação (ensaios A e B), atingindo quase a neutralidade aos 270 dias no ensaio $\mathrm{A}$ e um pouco ácido no ensaio B, evidenciando a insolubilização do ion cálcio. $\mathrm{O}$ pH do meio de cultura e do líquido de extração pela água se manteve na neutralidade.

A solubilização microbiana do $\mathrm{Ca}^{++}, \mathrm{Mg}^{++}$e $\mathrm{Fe}^{+++}$segue o modelo clássico conhecido como cinética tipo Michaelis, característico dos processos biológicos. As extrações continuam depois que a cultura cessa de crescer, sugerindo que a extração seja decorrente não propriamente da presença das células mas, antes, dos produtos do metabolismo microbiano. O metabolismo continua, mesmo na fase estaciónária do crescimento, pois as células estão vivas e metabolizam a sacarose para obter energia, tomando o nome de metabolismo secundârio. Nesse ponto, tendo cessada a síntese de proteínas e outras macromoléculas, que caracterizam o metabolismo da fase de crescimento exponencial, caso do $\mathrm{Mg}^{++}$e do $\mathrm{Fe}^{+++}$e reduzida a quantidade de sacarose, ocorre diminuição de outras enzimas e se inicia o metabolismo secundário.

A solubilização do $\mathrm{Ca}^{++}, \mathrm{Mg}^{++}$e $\mathrm{Fe}^{+++}$determinada pelos fungos decorre da ação dos produtos do metabolismo, seja indiretamente, pelo $\mathrm{pH}$, seja diretamente, pela ação de ácidos de outros produtos do metabolismo.

Outro ponto interessante é o consumo do cálcio pelos fungos, a ponto de mascarar a solubilização até atingir a fase estacionária. Isso prova que o meio usado é deficiente em $\mathrm{Ca}^{++}$, e este deve ser suplementado. $\mathrm{O}$ cálcio solubilizado da rocha supre a deficiência do cálcio do meio. Em trabalhos anteriores, já tinha sido evidenciada a influência do níquel (Ribeiro et al. 1969).

Em futuras experiências, esses fatores serão investigados mediante dosagem dos ions por espectrofotometria de absorção atômica. Nestas experiências é necessário também considerar a influência que a rocha exerce sobre o agente, acele- rando sua própria solubilização. É um processo auto-estimulado.

CONCLUSÕES É evidente a ação agressiva e significativa dos fungos sobre o hornblenda diopsidito, principalmente o Penicillium rotundum, com a solubilização do $\mathrm{Ca}^{++}$, $\mathrm{Mg}^{++}$e $\mathrm{Fe}^{+++}$. A ação desses fungos sobre a rocha não é direta, mas decorre dos produtos do metabolismo.

O Penicillium rotundum mostrou-se mais agressivo no ataque à rocha que o Aspergillus fumaricus. Aos 180 dias, aconteceu o contrário, o Aspergillus fumaricus ficou mais ativo com 270 dias de incubação, a atuação do Penicillium rotundum foi maior.

A ação da água também se fez notar, porém em menor proporção (Tab. 1). Os resultados parecem importantes quando se considera que a rocha utilizada provém de região de clima úmido e quente, onde há facilidade para a proliferação de fungos.

O tempo de cultivo das experiências poderia ter sido menor, se estes tivessem sido agitados, conforme verificou um dos autores (Ribeiro 1975). Mas preferiu-se um modelo de experiência mais condizente com o que ocorre em natureza, onde tais ações são lentas e repetidas.

A elevada tolerância dos fungos aos íons metálicos ( $\left.\mathrm{Fe}^{+++}\right)$em solução permite prever sua utilização nos processos hidrometalúrgicos extrativos.

As modificações verificadas nas lâminas de rocha podem ser explicadas admitindo que os produtos do metabolismo do fungo alteram a estrutura cristalina do mineral, passando a um material amorfo. Os autores ainda farão a determinação desse material amorfo com microscopia eletrônica. Estes dados concordam com os de Silverman \& Munõz (1970) obtidos com espectrografia de absorção atômica no infravermelho. O ataque é atribuído ao ácido produzido pelas cepas; o ácido tanto pode agir pelo íon hidrogênio livre, deslocando os elementos das redes cristalinas dos minerais, que constituem o hornblenda diopsidito, como pelo ânion citrato, que tem poder complexante (Ribeiro 1974).

Os fragmentos da rocha, submetidos ao ataque microbiano, foram analisados quimicamente, observando-se poucas modificações por se tratar de alteração superficial.

Agradecimentos Os autores agradecem ao CNPq - Conselho Nacional de Pesquisas pelo suporte financeiro, sem o qual não teria sido possível a realização desse trabalho e ao prof. Ilson Guimarães Carvalho, coordenador do Curso de Pós-Graduação em Geociências, por ter facilitado os meios para a realização do mesmo.

\section{REFERENNCIAS BIBLIOGRÁFICAS}

BOYLE, J.R. \& VOIGT, G.K. - 1967 - Alteration by chemical and biological treatment. Science $155: 193-195$.

BOYLE, J.R. \& VOIGT, G.K. - 1973 -

GUIMAR ÃES, D. - 1969 - Petrografia das rochas metamórficas. Esc. Nac. de Min. e Met., Ouro Preto, 96 p.

LOCZY, L. \& LADEIRA, E.A. - 1976 - Geologia Estrutural e Introdução à Geotectônica. São Paulo, Edgard Blucher. 528 p.

MASCARENHAS, J.F. - 1979 - Estrutura Geotectônica do Précambriano do Estado da Bahia. In: GEOLOGIA E RECURSOS MINERAIS DO ESTADO DA BAHIA, Textos Básicos, SME/ CPM; BA, 2 : 57-157.

OTTOW, G.C. \& KLOPOTEK, A. VON - 1969 - Enzimatic reduction iron oxide by fungi. Appl. Microb. 18 (1) :41-43.

RIBEIRO, R.M.; MARTELLI, H.L.; ROSEMBERG, J.A. - 1969 Dosagem microbiológica do níquel em amostras de solo. Rev. Bras. Farmácia 3 : 73-75.

RIBEIRO, R.M. - 1974 - Alteração por fungos de minerais con- tendo ferro. (Tese de Mestrado - Instituto de Geociências, UFBA). Salvador, BA.

RIBEIRO, R.M. - 1975 - Influência da agitação na solubilização microbiana de minerais, Rev. de Tecnologia $6: 76$.

RIBEIRO, R.M.; SANTOS, A.M.; MARTELLI, H.L. - 1976 - Alteração microbiana em rocha: solubilização do ferro por ação de fungos em diabásios. Rev. Bras. Geoc. 6 (3) :146-155.

SILVERMAN, M.P. \& MUNÕZ, E.T. - 1970 - Fungal attack on rock solubilization and altered infrared spectra. Science 169: 983-987.

TANNER DE OLIVEIRA, M.A.F. \& CONCEIÇÃO, H. - $1982-$ Metamorfismo de alto grau da faixa costeira de Salvador, BA. In: CONG. BRAS. GEOL., 22, Salvador. Anais..., Salvador, BA, 2 :603-616.

MANUSCRITO Recebido em 25 de março de 1985 Revisão aceita em 18 de dezembro de 1985 